\author{
Military Technical College \\ Kobry Elkobbah, Cairo, \\ Egypt.
}

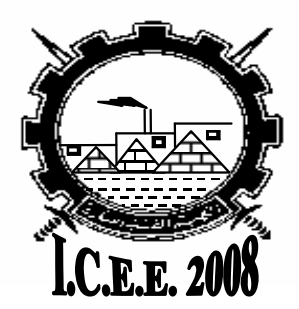

$4^{\text {th }}$ International Conference On Chemical \& Environmental Engineering 27-29 May 2008

\title{
PERFORMANCE OF EXPLOSIVELY FORMED PROJECTILES
}

\author{
M. M. Ismail*
}

\begin{abstract}
Explosively formed projectiles offer considerable future potential for demolition applications, since their long stand-off capability allows them to be used in situations where it is dangerous to use contact demolition techniques. Nowadays, the EFP charges occupy an important position in armor-piercing ammunition.

In the design of explosively formed projectiles warhead, there are many parameters which affect the projectile performance. These include geometrical configuration such as liner contours, casing thickness, charge dimensions, etc. and material properties. Due to the large number of parameters, both experimental and numerical techniques are required.

In this thesis, an experimental program was performed through which firing tests for the prototype models and the final design with different refinements to the design technique were performed. Firing tests were carried out from different stand-off distances into a specified RHA target to evaluate the overall performance of the EFP. Then EFP physical formation and penetration was investigated numerically using AUTODYN-2D hydrocode.

Comparison of experimental and numerical results was presented to check the reliability of the obtained results. In despite of some discrepancies, experimental and numerical results were found to be in good agreement, especially in terms of overall EFP performance.
\end{abstract}

